\title{
MEDIACIÓN DE CONSUMO: UNA PERSPECTIVA ESPAÑOLA Y EUROPEA*
}

\section{CONSUMER MEDIATION: A SPANISH AND EUROPEAN PERSPECTIVE}

\author{
ELVIRA MARUGÁN ESCOBEDO \\ Universidad de Extremadura
}

Recibido: 05/05/2019 Aceptado: 18/09/2019

\section{RESUMEN}

En el presente trabajo comenzamos analizando las generalidades de la mediación como institución, a modo de introducir la cuestión nuclear de nuestro estudio: la mediación de consumo. Posteriormente, estudiaremos en profundidad todos los aspectos de esa mediación en el ámbito del Derecho de consumo, de tal forma que analizaremos la legislación que le afecta, tanto a nivel comunitario, como estatal y autonómico y todos los aspectos que de esa normativa derivan y que se aplican en todo caso a los procedimientos de mediación de consumo. Nos centraremos especialmente en los principios aplicables al procedimiento, prestando una especial atención a la dicotomía que se da entre la voluntariedad y la obligatoriedad de someterse a un procedimiento de mediación como paso previo al acceso a la vía judicial, analizando lo establecido al respecto por las disposiciones legales, pero también por la jurisprudencia y la doctrina.

\footnotetext{
* El presente trabajo es la culminación del Proyecto de Investigación con el que concurrimos a la convocatoria de Becas de Colaboración en Departamentos del Ministerio de Educación y Formación Profesional del año 2018, habiendo sido beneficiaria de una de dichas becas en el Departamento de Derecho Público de la Facultad de Derecho de la Universidad de Extremadura, bajo la dirección del Profesor Dr. Jesús Conde Fuentes.
} 
Por último, realizaremos un breve estudio sobre los medios online de resolución alternativa de litigios en materia de consumo, haciendo una especial mención a la Plataforma Europea de resolución de litigios en línea.

Palabras clave: Derecho de consumo, acceso a los tribunales, consumidores, mediación; mediación de consumo, mediación obligatoria, resolución alternativa de litigios, resolución de litigios en línea.

\section{ABSTRACT}

In our paper, we begin studying the mediation in general, as an institution, in order to introduce the nuclear issue of our study: consumer mediation. Subsequently, every aspect of this type of mediation will be analyzed in depth: the legislation that affects it, both at the European, state and regional level, as well as all the aspects that infer from this regulation, which apply, in any case, to consumer mediation procedures. We will particularly focus in the principles and rules applicable to the procedure, paying special attention to the dichotomy between voluntariness and obligatoriness regarding submit a mediation procedure as a previous step to the Court access, analyzing not only the legal prescripts on this field, but also the jurisprudence and the doctrine. Finally, a brief study will be made about the online dispute resolution methods in the consumption law field, making a special mention to the European Online Dispute Resolution Platform.

Keywords: Consumption Law, Court access, consumers, mediation, consumer mediation, mandatory mediation, alternative dispute resolution, online dispute resolution.

Sumario: 1. Introducción. 2. La mediación: nociones generales: 2.1. Concepto y diferencias con otros medios de resolución de conflictos; 2.2. La Ley 5/2012 de Mediación en Asuntos Civiles y Mercantiles. 3. La mediación de consumo: 3.1. Ámbito competencial y normativo; 3.2. La Ley 7/2017 relativa a la resolución alternativa de litigios en materia de consumo. 4. La resolución de conflictos online en materia de consumo. La Plataforma Europea de resolución de litigios en línea. 5. Conclusiones. 


\section{INTRODUCCIÓN}

Es innegable la importancia del Derecho de Consumo en general y de la resolución extrajudicial de conflictos en particular (como es la mediación), en la vida diaria de cualquier ciudadano. La legislación en materia de protección de consumidores y usuarios es fundamental en la actualidad, pues se observa una evidente disparidad en las relaciones de las empresas y los consumidores, ya que las primeras cada vez son más grandes y tienen más poder, dejando así a los consumidores al arbitrio de lo que ellas dispongan. Por ello, se deben establecer límites y arbitrar mecanismos para hacer efectivos todos los derechos que se les reconocen a los consumidores por el mero hecho de tener ese estatus. Así, la mediación de consumo es uno de esos mecanismos que puede articularse con el fin de aumentar y mejorar la protección de los consumidores, y ello porque en la mayoría de las disputas que se producen en este ámbito no son apropiadas para gestionarlas por vía judicial, ya que suelen consistir en reclamaciones de cantidades muy pequeñas, y al consumidor no le compensa un procedimiento judicial, fundamentalmente por motivos de tiempo y de costes. La mediación, al igual que otros medios alternativos de resolución de litigios, resulta idónea en esta materia, ya que permite disminuir los plazos y ahorrar costes.

Teniendo todo ello en cuenta, a lo largo del presente trabajo se analizará, en primer lugar, todo lo relativo a la institución de la mediación en general, partiendo de la base de la Ley 5/2012, de 6 de julio, de mediación en asuntos civiles y mercantiles. Si bien esta norma no resultaba aplicable a la mediación en consumo porque -de hecho- la prohibía, como ya se verá, ha de tenerse en cuenta, pues sienta las bases de su regulación. También se estudiarán las diferencias que se pueden observar entre la mediación y otros medios de resolución de conflictos, tanto los autocompositivos como los heterocompositivos.

Seguidamente, se tratará en profundidad la mediación de consumo, con lo que lo primero a abordar será el ámbito competencial y normativo 
en la materia, pues el Derecho de Consumo y la protección de consumidores y usuarios son competencias compartidas entre la Unión Europea, el Estado español y las Comunidades Autónomas, lo que comporta una gran diversidad normativa en la materia. No obstante, nos referiremos en especial a una norma concreta, cual es la reciente Ley 7/2017, de 2 de noviembre, relativa a la resolución de litigios en materia de consumo, que, trasponiendo la Directiva 2013/11/UE del Parlamento Europeo y del Consejo, de 21 de mayo de 2013, relativa a la resolución alternativa de litigios en materia de consumo, se encarga de regular todo lo relativo a la mediación de consumo, en tanto en cuanto es un medio alternativo de resolución de conflictos en este ámbito. La aprobación de esta norma comportó la derogación de la prohibición del uso de la mediación en el ámbito del Derecho de Consumo que hacía la Ley 5/2012.

Con todo, atenderemos especialmente a los principios aplicables a los procedimientos, y más concretamente a la voluntariedad de someterse a los mismos, ya que resulta sumamente trascendente en cuanto a la protección del consumidor por los motivos que más adelante se desarrollarán; así como a las entidades de resolución alternativa de litigios, estudiando los requisitos aplicables para su acreditación y las exigencias impuestas a las personas físicas que se encarguen de resolver los procedimientos gestionados por las primeras.

Por último, se efectuará una referencia a los medios online de resolución de litigios con consumidores. Dada la importancia de las nuevas tecnologías en nuestra vida diaria no se puede olvidar la posibilidad que se nos ofrece de tramitar las reclamaciones de consumo por vías electrónicas. Así, se hará referencia a la mediación electrónica, que es, en la actualidad, un proyecto de futuro, y además se estudiará la Plataforma Europea de resolución de litigios en línea. 


\section{LA MEDIACIÓN: NOCIONES GENERALES}

2.1. CONCEPTO Y DIFERENCIAS CON OTROS MEDIOS DE RESOLUCIÓN DE CONFLICTOS

Establecer un concepto de mediación no es sencillo. La ley 5/2012, de 6 de julio, de mediación en asuntos civiles y mercantiles, da una definición de mediación en su primer artículo. Así, se entiende por mediación, como concepto legal, "aquel medio de solución de controversias, cualquiera que sea su denominación, en que dos o más partes intentan voluntariamente alcanzar por sí mismas un acuerdo con la intervención de un mediador". Sin embargo, a pesar de la claridad y sencillez de la definición expuesta por la ley, la doctrina difiere de esa definición, entendiendo algunos autores que establecer un concepto de mediación es una tarea extremadamente compleja por factores tales como la inexistente tradición de esta figura en nuestro ordenamiento, las distintas regulaciones que se le da dependiendo del ámbito de aplicación a que nos refiramos o incluso dependiendo del territorio en que se quiera emplear ${ }^{1}$. Además, otros autores propugnan que la definición legal no es del todo correcta, debido, esencialmente, a dos factores. En primer lugar, porque alude a cualquier método de resolución de conflictos, no diferenciando la mediación de otros medios como la conciliación que pueden ser confundidos con la primera; y, en segundo lugar, porque realmente la mediación no supone la solución de la controversia que a ella se somete, pues con este método no se garantiza esa solución, sino que dependerá de la voluntad de las partes ${ }^{2}$. Por ello, aquellos que defienden esta idea definen la mediación como un "procedimiento confidencial de gestión de conflictos en el que un tercero profesional, neutral e imparcial, que carece de autoridad para imponer una solución, ayuda a las partes a

\footnotetext{
1 Helena Soleto Muñoz, "La mediación conectada con los tribunales”, en Mediación y resolución de conflictos. Técnicas y ámbitos. Coordinado por Emiliano Carretero Morales y Cristina Ruíz López. (Madrid: Tecnos, 2017), 493-510. En el mismo sentido, pero con posterioridad, vid. Emiliano Carretero Morales, La mediación civil y mercantil en el sistema de justicia (Madrid: Dykinson, 2016), 78.

2 Carretero Morales, La mediación civil y mercantil..., 78-79.
} 
resolver voluntariamente una disputa o a negociar una transacción adecuada a sus propios intereses y necesidades".

En cualquier caso, tomaremos para el estudio de la materia el concepto de mediación contenido en la legislación por ser este el vigente e imperativo. Con ello, se establecen claras diferencias entre la mediación y otros medios de resolución de conflictos. La mediación se configura como un método autocompositivo, esto es, en el que son las propias partes en conflicto las que deciden someterse a ella de manera voluntaria. Otros métodos autocompositivos son la negociación y la conciliación. En el caso de la negociación, la diferencia principal con la mediación es que en la primera no hay un tercero que intervenga en la solución del litigio, sino que son las partes por sí mismas las que tratan de llegar a un acuerdo. Por su parte, la conciliación se da con el objetivo de evitar un procedimiento judicial o terminar uno ya iniciado. Es por ello por lo que el tercero interviniente es un Juez de Paz o un Letrado de la Administración de Justicia ${ }^{3}$, con lo que la diferencia fundamental con la mediación se basa en que en esta última el tercero no es parte del sistema de justicia, sino que el mediador es -simplemente- un tercero imparcial elegido por las partes.

Sin embargo, no solo se diferencia la mediación de otros métodos autocompositivos de resolución de litigios, sino que también pueden destacarse sus diferencias respecto de las vías heterocompositivas, cuales son la jurisdicción y el arbitraje. La diferencia esencial, por su entidad, ya que comporta la naturaleza de unas y otras vías, es la eficacia de la decisión. Así, en el caso de la mediación, la solución no es vinculante para las partes, sino que se atendrán a ella solo de manera voluntaria, mientras que tanto las resoluciones derivadas de procedimientos de arbitraje

3 En la actualidad, la conciliación se regula en los arts. 139 y ss. de la Ley 15/2015 de Jurisdicción Voluntaria. La conciliación es voluntaria, encontrándose a disposición de las partes para obtener acuerdos de manera amistosa, evitando así posibles contiendas judiciales. Además, no obsta a que las partes puedan llegar a los mismos acuerdos mediante la intervención de otros operadores jurídicos como Notarios o Registradores. 
como las sentencias tras un procedimiento jurisdiccional son vinculantes, hasta el punto de constituirse como títulos ejecutivos ${ }^{4}$.

\subsection{LA LEY 5/2012 DE MEDIACIÓN EN ASUNTOS CIVILES y MERCANTI-} LES

En materia civil y mercantil, la institución de la mediación se regula en la Ley 5/2012, de 6 de julio, de Mediación en Asuntos Civiles y Mercantiles 5 . El preámbulo de la ley justifica la propia existencia de la institución, en primer lugar, como canalización del derecho a la tutela de los derechos del ciudadano, configurando la mediación como alternativa a la vía jurisdiccional o la arbitral, respecto de las cuales, además, expresa la necesidad de delimitación. Así, como ya se ha mencionado, el artículo 1 de esta norma define la mediación como un medio de resolución de conflictos mediante el cual las partes tratan de, voluntariamente, llegar a un acuerdo con la intervención de un mediador. En su segundo artículo se establece el ámbito de aplicación, refiriéndose a la materia civil y mercantil, pero excluyendo expresamente la mediación penal, la mediación con las Administraciones Públicas y la mediación laboral. Mención especial requiere la exclusión realizada en ese mismo artículo referente a la mediación en materia de consumo, pues dicha referencia quedó suprimida mediante la disposición final séptima de la Ley 7/2017 relativa a la Resolución Alterativa de Litigios en Materia de Consumo. Esa exclusión fue considerada por algunos autores como una interpretación errónea que efectuó el legislador español del Considerando número 11 de la Directiva 2008/52, puesto que esta permitía a los Estados estructurar la

4 Con reservas respecto al arbitraje, pues el laudo arbitral deberá ser homologado judicialmente (art. 25 de la ley 5/2012, de 6 de julio, de mediación en asuntos civiles y mercantiles).

5 Esta ley es fruto de la trasposición de la Directiva 2008/52/CE del Parlamento Europeo y del Consejo, de 21 de mayo de 2008, sobre ciertos aspectos de la mediación en asuntos civiles y mercantiles, si bien no se adaptó esta norma a nuestro ordenamiento jurídico en el plazo estipulado, esto es, hasta mayo de 2011 como límite máximo. Como viene siendo costumbre, la trasposición no se produjo hasta la promulgación de urgencia del Real Decreto Ley 5/2012, de 5 de marzo, de mediación en asuntos civiles y mercantiles. Este texto fue posteriormente convalidado como ley dando lugar a la vigente ley $5 / 2012$. 
mediación en cualquier ámbito civil y mercantil, incluida la materia de consumo, como estos considerasen oportuno de acuerdo con su normativa interna siempre que se respetase la base de la propia Directiva ${ }^{6}$.

De acuerdo con esta ley, la mediación ha de sujetarse a una serie de principios, cuales son la voluntariedad, en tanto en cuanto no se podrá obligar a nadie a someterse a ella; la igualdad de partes y la imparcialidad y neutralidad del mediador; y la confidencialidad, ya que ni el mediador ni las partes podrán revelar información relativa al procedimiento.

En cuanto a los sujetos intervinientes en la mediación, básicamente, son dos: las partes en conflicto que deciden someterse al proceso de manera voluntaria y el tercero que ejerce las funciones de mediador. En lo que respecta a las partes, tienen plena libertad en lo que al proceso de mediación se refiere, pues se configurará como estimen conveniente, si bien deberán atender en sus actuaciones a los principios de lealtad, buena fe y respeto mutuo, no debiendo ejercitar acciones judiciales o extrajudiciales de ningún tipo en relación con el objeto que se somete a mediación en tanto en cuanto no se sustancie esta, exceptuando las solicitudes de medidas cautelares o urgentes que resulten imprescindibles7.

Por su parte, el mediador podrá ser una persona física o bien tomar la forma de las llamadas instituciones mediadoras, que podrán ser públicas o privadas. No obstante, en caso de que se trate de una de estas personas jurídicas, siempre deberá designarse a una persona física que cumpla con los requisitos establecidos en la ley para poder ejercer como mediador. Dichos requisitos, que ha de cumplir cualquier sujeto que pretenda desempeñar las funciones de mediador, se contienen en el artículo 11 de la Ley 5/2012 de mediación en asuntos civiles y mercantiles, y son: estar en situación de pleno ejercicio de sus derechos civiles sin que en él

6 A este respecto, Fernando Esteban De La Rosa, "La vertebración del régimen español de la mediación de consumo en el marco del Derecho europeo", Revista de los Estudios de Derecho y Ciencia Política 25 (2017): 22.

7 Ignacio Díez-Picazo Giménez, "El arbitraje y la mediación”, en Curso de Derecho Procesal Civil II. Parte Especial, dir. por Andrés de la Oliva Santos y Jaime Vegas Torres (Madrid: Editorial Universitaria Ramón Areces, 2014), 585-612. 
concurra ningún impedimento legal por razón del ejercicio de su profesión; contar con un título universitario oficial o con formación profesional superior, y, en cualquier caso, con formación específica en el ámbito de la mediación ${ }^{8} ; \mathrm{y}$, por último, deberá suscribirse un seguro cuya cobertura comprenda la eventual responsabilidad civil que pueda surgir por su actuación respecto de los conflictos en los que intervenga como mediador. Además de todo ello, el mediador tendrá que observar ciertas reglas y principios en su actuación, que son los contenidos en el artículo 13 de la ya mencionada ley. Así, deberá facilitar en todo momento la comunicación entre las partes, tender, de manera activa, a su acercamiento o manifestarles cualquier circunstancia que pudiera comprometer su imparcialidad. Se contempla la posibilidad de renuncia del mediador, en cuyo caso deberá este entregar a las partes un acta en la que se refleje su deseo de renunciar.

\section{LA MEDIACIÓN DE CONSUMO}

\section{1. ÁMBITO COMPETENCIAL Y NORMATIVO}

Si se habla de Derecho de Consumo, el primer ámbito competencial y normativo que ha de tenerse en cuenta es el comunitario. La Unión Europea tiene, en virtud del artículo 4.2.f) del Tratado de Funcionamiento de la Unión Europea, la competencia compartida con los Estados miembros en materia de protección de los consumidores. Por ello, gran parte de la normativa en la materia proviene de normas comunitarias. En el ámbito concreto de la mediación de consumo encontramos la Directiva 2013/11/UE del Parlamento Europeo y del Consejo, de 21 de mayo de 2013, relativa a la resolución alternativa de litigios en materia de consumo. Fundamental es también la actividad del Tribunal de Justicia de

8 De acuerdo con el citado artículo, esta formación específica se adquirirá mediante la realización de uno o varios cursos que deberán haber sido impartidos por parte de instituciones acreditadas a tal efecto. Esta formación acreditará al mediador para poder ejercer sus funciones en cualquier parte del territorio nacional. 
la Unión Europea en materia de consumo, pues ha modificado en numerosas ocasiones la normativa de protección de consumidores del ordenamiento español, así como la jurisprudencia de nuestros tribunales ${ }^{9}$.

No obstante, como se ha mencionado, esa competencia en protección de los consumidores es compartida con los Estados miembros, con lo que también España tiene competencias legislativas en la materia. En este concreto ámbito, en resolución alternativa de litigios consumidores, ha de mencionarse la reciente Ley 7/2017, de 2 de noviembre, relativa a la resolución alternativa de litigios en materia de consumo, que traspone esa Directiva 2013/11 de la Unión Europea. Esta ley permitió que la mediación pudiera aplicarse a conflictos en los que intervengan consumidores, pues anteriormente venía específicamente prohibido el uso de este método por la Ley 5/2012, como ya se ha explicado con anterioridad.

Sin embargo, la competencia estatal en el caso de España no está compartida únicamente con la Unión Europea, sino que las Comunidades Autónomas también tienen adquiridas competencias en la materia. De hecho, algunas contemplan la competencia exclusiva en materia de protección de consumidores en sus respectivos estatutos de autonomía. El mejor ejemplo a este respecto es Cataluña, pues en 2010 se aprueba el Código de Consumo de Cataluña, mediante Ley 22/2010, de 20 de julio. Esta Comunidad Autónoma tiene adquiridas competencias exclusivas en materia de consumo en su estatuto de autonomía, concretamente en su artículo 123. Por ello, adoptó esta norma con el objetivo de dotar a los consumidores y usuarios de una mayor protección en su ámbito territorial, siempre, por supuesto, teniendo en cuenta la normativa europea. Por su parte, Extremadura tiene igualmente adquiridas competencias

9 Piénsese en la Sentencia del Tribunal de Justicia de la Unión Europea (Gran Sala), de 21 de diciembre de 2016 (TJCE 2016 \309), referente a la nulidad de las cláusulas suelo. Dicha sentencia fue producto de una serie de cuestiones prejudiciales planteadas ante dicho tribunal tras la sentencia del Tribunal Supremo español 241/2013, de 9 de mayo. Esta última declaraba la nulidad de las cláusulas suelo, y prohibía su uso a las entidades en los contratos de préstamo hipotecario, pero denegaba la retroactividad de su decisión. El Tribunal de Justicia de la Unión Europea, sin embargo, entendía, de una manera más coherente, que la nulidad comportaba necesariamente la retroactividad, y, por tanto, la obligación de las entidades de devolver a los consumidores las cantidades indebidamente abonadas en aplicación de las cláusulas suelo, cuestionando así la protección que el consumidor recibe en España. 
exclusivas en materia de consumo y protección de consumidores y usuarios en virtud del artículo 9.1.18 del estatuto de autonomía. En desarrollo de esa previsión, encontramos, por ejemplo, la reciente ley 6/2019, de 20 de febrero, del Estatuto de las personas consumidoras en Extremadura. A nivel institucional, se puede hablar del Instituto de Consumo de Extremadura, que tiene funciones ejecutivas de las competencias en la materia adquiridas por la Comunidad Autónoma ${ }^{10}$, así como la Junta Arbitral de Consumo de Extremadura, que es supervisada por el Instituto y que es la entidad de resolución alternativa de litigios de carácter público que se encarga de conocer de los conflictos en los que intervienen consumidores en el ámbito territorial de nuestra Comunidad Autónoma, siempre y cuando las partes quieran someterse a procedimientos alternativos como la mediación o el arbitraje.

3.2. LA LEY 7/2017 RELATIVA A LA RESOLUCIÓN ALTERNATIVA DE LITIGIOS EN MATERIA DE CONSUMO

Con el objetivo de trasponer al ordenamiento jurídico español la Directiva 2013/11/UE, del Parlamento Europeo y del Consejo, de 21 de mayo de 2013, se aprueba la Ley 7/2017, de 2 de noviembre, relativa a la resolución alternativa de litigios en materia de consumo. Esta ley comportó que la disposición relativa a la exclusión de la mediación en supuestos de litigios con consumidores y usuarios que contenía la Ley 5/2012 de mediación en asuntos civiles y mercantiles dejara de tener virtualidad.

Si se atiende a lo expuesto en el preámbulo de la Ley 7/2017, se entiende la motivación tanto de la propia ley como de la directiva que traspone. Se expone en dicho preámbulo la evolución de la protección de los

10 De acuerdo con el artículo 4 del Decreto 214/2008, de 24 de octubre, mediante el cual se aprueban los estatutos del Instituto de Consumo de Extremadura, estas competencias son, entre otras: asesoramiento al Consejo de Gobierno de Extremadura en materia de consumo; información a los consumidores y usuarios sobre sus derechos, impulsando y promoviendo su formación en la materia; fomento de prácticas de consumo ético, justo y ecológicamente responsable; o potenciar el uso de la mediación y el arbitraje para resolver los conflictos con consumidores. 
derechos de los consumidores en el ámbito de la Unión Europea, distinguiéndose dos etapas. Una primera etapa en la que simplemente se reconocieron los derechos de los consumidores por el hecho de serlo, así como los principios rectores de la normativa al respecto; y una segunda etapa en la que, tras constatar que el mero reconocimiento no era suficiente, se comenzaron a integrar mecanismos para hacerlos efectivos. Aun así, se observaban dificultades en el acceso a la justicia ordinaria por parte de los consumidores, constatándose, así, como insuficientes los medios que se habían articulado. Por ello, se empiezan a dictar normas relativas a la resolución extrajudicial de los litigios surgidos entre los consumidores y empresarios. Con todo ello, se llega a la aprobación de la Directiva 2013/11/UE y a la ley que la traspone, cuyo estudio nos ocupa. Ambas normas garantizan, en definitiva, la existencia de una vía alternativa de resolución de conflictos para los consumidores, cual es la de la mediación. Así, podrán los consumidores, en cualquier caso, someterse a la mediación con la garantía de que se llevará a cabo mediante instituciones de resolución alternativa de litigios debidamente acreditadas y bajo la sujeción a una serie de principios que garantizarán en todo momento la defensa de sus intereses.

Con todo, se aprueba en el ámbito nacional la ley 7/2017 que se centra básicamente en dos materias que serán objeto de estudio por este trabajo. En primer lugar, la norma expone los principios rectores a los que deberá sujetarse cualquier procedimiento alternativo de resolución de litigios en materia de consumo, ya sea mediación, arbitraje u otro distinto. $\mathrm{Y}$, en segundo lugar, la ley se encarga de regular todo lo relativo a las denominadas entidades de resolución alternativa de litigios, que serán las que se encarguen de tramitar el procedimiento. De ambas cuestiones se ocupa la ley sin una sistemática clara, pues comienza abordando la acreditación de las entidades de resolución, pasando a tratar los principios rectores en el marco del procedimiento para volver, con posterioridad, a regular los requisitos exigibles a las personas encargadas de la resolución y al procedimiento para la acreditación de las entidades y sus 
obligaciones. En nuestra opinión, hubiera sido más coherente regular primero todos los requisitos, tanto los atinentes a las entidades como los que respectan a las personas encargadas de la resolución, así como de los procedimientos de acreditación y, después, pasar a los aspectos concernientes al procedimiento de resolución per se, como son los principios aplicables al mismo.

3.2.1. Los principios aplicables a los procedimientos de resolución alternativa de conflictos en materia de consumo

La ley 7/2017, en la Sección $2^{\text {a }}$ del Capítulo I del Título I, recoge una serie de principios. En primer lugar, contempla ciertos principios que la propia ley califica como rectores. Lo hace concretamente en el artículo 8 y dichos principios son los de independencia, imparcialidad, transparencia, eficacia y equidad. Pero, además, la ley recoge otros principios, si bien, de acuerdo con el mismo título de la Sección $2^{\mathrm{a}}$, no se consideran principios como tal, sino requisitos que ha de seguir el procedimiento. Sin embargo, estas premisas han de ser consideradas como principios, pues, de hecho, el Anteproyecto de Ley los calificaba como tales y no como requisitos ${ }^{11}$, y son los siguientes: voluntariedad frente a obligatoriedad, defensa y asesoramiento de las partes, coste y duración del procedimiento, facilidad de acceso al mismo, igualdad y contradicción de las partes y la ineficacia para el consumidor de acuerdos previos.

Los principios rectores: Como ya se ha mencionado, los principios que la ley califica como rectores respecto de los procedimientos de resolución alternativa de litigios en materia de consumo, se contienen en el artículo 8, y son los principios de independencia, imparcialidad, transparencia, eficacia y equidad. Este artículo simplemente los enuncia, pero no los desarrolla, sino que se van mencionándose a lo largo de todo el cuerpo normativo. Así, aparecen la independencia e imparcialidad, por

11 En este sentido, Alicia Agüero Ortiz, "La transposición de la Directiva 2013/11/UE al ordenamiento jurídico español a través de la Ley 7/2017 de 2 noviembre”, en La resolución de conflictos con consumidores: de la mediación a las ODR, dir. por Inmaculada Barrals Viñals (Madrid: Reus, 2018), 41-74. 
ejemplo, en el artículo 23 en referencia a los requisitos que han de cumplir las personas encargadas de la resolución del litigio; en cuanto a la transparencia, se contempla en el artículo 35 respecto de las obligaciones de las entidades de resolución acreditadas; respecto de la eficacia, se menciona en cuanto a los pactos previos que puedan darse entre el consumidor y el empresario, diferenciando entre los procedimientos con resultados vinculantes y no vinculantes; y en lo que respecta a la equidad, también se menciona en el marco de las obligaciones de las entidades en el artículo $35^{12}$.

Voluntariedad: A la voluntariedad como principio $^{13}$ se refiere el artículo 9 de la Ley 7/2017, estableciendo que ninguna de las partes en conflicto, ni consumidor ni empresario, podrán ser obligadas a someterse a un procedimiento de resolución alternativa de litigios. No obstante, se contempla una excepción a esta máxima de la voluntariedad, cual es la de que una norma especial establezca la obligatoriedad de sometimiento a estos procedimientos.

Este principio de voluntariedad absoluta es una decisión del legislador español, pues la Directiva 2013/11 que traspone la Ley 7/2017 establecía la posibilidad de que los Estados miembros impusieran la obligatoriedad si así lo consideraban oportuno, siempre y cuando ello no supusiera un impedimento para ninguna de las partes respecto del acceso al sistema judicial. Teniendo esto en cuenta, no se entiende muy bien por qué el legislador nacional ha tomado esta decisión, ya que supone una rémora para la defensa de los derechos del consumidor, sobre todo en cuanto a la mediación ${ }^{14}$. La única explicación al respecto es que esa voluntariedad se basa en la previsión que hace en la materia la Ley 5/2012, de 6 de julio, de mediación en asuntos civiles y mercantiles, pues declara,

12 Todo ello se abordará con más profundidad, desarrollándolo, en los apartados posteriores del presente trabajo que correspondan en cada caso.

13 La ley se refiere a la voluntariedad como requisito y no como principio, pero, como ya se ha explicado, sería más adecuado considerar todos esos requisitos de la Sección $2^{\mathrm{a}}$ como principios.

14 Ello porque la mediación es más económica y rápida, con lo que acudir a ella por parte de los consumidores va a resultar siempre más atractivo que hacerlo al arbitraje y, por supuesto, a la vía judicial. 
en su artículo 6, que la mediación es voluntaria, sin perjuicio de los pactos previos al conflicto que se puedan efectuar. Declara la voluntariedad incluso respecto de la permanencia en el procedimiento y de su conclusión con un acuerdo.

Sin embargo, todo lo anterior lo único que supone es una merma en los derechos y garantías del consumidor, que podrá verse obligado a acudir a un proceso más costoso, como es la vía judicial ${ }^{15}$, para ver satisfecha su reclamación en el caso en el que el comerciante se niegue a someterse a un procedimiento de mediación. Esta cuestión se solventaría si el legislador le impusiera a la empresa la obligación de intentar, con carácter previo al proceso judicial, la mediación, o, al menos, la asistencia a una sesión informativa previa, en la que ambas partes recibirán toda la información relativa al procedimiento de mediación, pudiendo tras ello decidir sobre la conveniencia de someterse a ella o bien escoger otro medio de resolución, ya sea judicial o no. Incluso en materia de arbitraje, la solución podría venir dada por la obligatoriedad de adherirse al sistema arbitral de consumo. La prueba de que la voluntariedad para ambas partes perjudica enormemente al consumidor la dan los datos estadísticos, pues en aquellos países en los que se ha impuesto la obligatoriedad, como son Italia o Francia, los procedimientos alternativos, y, en concreto, los de mediación, son mucho más numerosos que en aquellos que se instaura la voluntariedad plena.

Estas obligaciones de asistencia a la sesión informativa previa o de adhesión al sistema arbitral de consumo, entre otras que podrían

15 Como ejemplo de esto, podría hablarse del sistema extrajudicial para la reclamación de las cantidades indebidamente abonadas en concepto de cláusulas suelo que articuló el Real Decreto Ley 1/2017, de 20 de enero, de medidas urgentes de protección de consumidores en materia de cláusulas suelo. Este sistema suponía una vía alternativa de resolución de los litigios ocasionados por el uso de esas cláusulas abusivas en los contratos de préstamo hipotecario. Sin embargo, la voluntariedad se estableció para las dos partes, tanto para el consumidor como para las entidades bancarias, con lo que, al final, la decisión la tomaba en exclusiva esta última, pues, además, se les concedieron muchas prerrogativas en la materia (fijación de plazos, establecimiento de la forma o la posibilidad de no responder a la reclamación, entre otras). Al respecto, vid. Jesús Conde Fuentes, "El procedimiento extrajudicial para la restitución de las cantidades pagadas en aplicación de las cláusulas suelo", Revista de Derecho Civil 4 (2017): 219-233. 
proponerse, deberían tenerse en cuenta no ya por el legislador nacional, sino por los distintos legisladores de las Comunidades Autónomas, ya que juegan un papel fundamental en materia de protección de los consumidores ${ }^{16}$. Esto iría en consonancia con lo previsto en la Ley 7/2017 respecto a la voluntariedad, pues la excepciona a que una ley especial establezca la obligatoriedad. El ya mencionado Código de Consumo de Cataluña realizó el primer intento en la materia, al establecer la obligatoriedad de acudir con carácter previo a un procedimiento de mediación como requisito de procedibilidad para admitir a trámite reclamaciones administrativas o demandas en vía judicial sobre créditos y préstamos hipotecarios. Sin embargo, el Tribunal Constitucional ${ }^{17}$ anuló por inconstitucionales partes de ese precepto, ya que entendía que violaba el reparto competencial entre Estado y Comunidades Autónomas, en tanto en cuanto la legislación procesal es competencia exclusiva del Estado en virtud del artículo 149.1.6 de la Constitución. Lo positivo de este pronunciamiento es que declara la inconstitucionalidad por la invasión competencial, ya que imponía un requisito de procedibilidad, pero no por declarar la obligatoriedad, con lo que no se cuestiona ya la validez de este aspecto.

De otro lado, no podemos obviar que la dicotomía entre voluntariedad y obligatoriedad respecto de los procedimientos de resolución alternativa de conflictos no puede referirse en exclusiva al acceso a ellos como

16 Si bien no se contempla expresamente esta posibilidad en el artículo 148 de la Constitución, todas las Comunidades Autónomas han asumido competencias en materia de consumo en sus Estatutos de Autonomía, pues tampoco declara el artículo 149 la competencia exclusiva del Estado en la materia. Ello porque la realidad es que el Derecho de Consumo se encuentra integrado por multitud de materias, con lo que afecta a varios títulos competenciales. A esta imprecisión trató de poner fin la redacción original de la Ley General para la Defensa de los Consumidores y Usuarios efectuando en su articulado un reparto competencial en la materia dentro de su articulado entre el Estado, las Comunidades Autónomas e incluso los entes locales. Sin embargo, ese reparto fue recurrido ante el Tribunal Constitucional, resolviéndose mediante la sentencia 15/1989, de 26 de enero. En definitiva, las Comunidades Autónomas pueden, y de hecho así lo han llevado a cabo, asumir competencias en materia de consumo, si bien hay que tener en cuenta ámbitos normativos superiores como son la Unión Europea y el Estado, no pudiendo obviar la necesidad de comunicación y cooperación entre todas estas instituciones para dar una efectiva protección a consumidores y usuarios. En este sentido, Jesús Conde Fuentes, "La adaptación del derecho español al marco europeo de resolución alternativa de litigios en materia de consumo", en Adaptación del Derecho procesal español a la normativa europea y a su interpretación por los tribunales, dir. por Fernando Jiménez Conde (Valencia: Tirant lo Blanch, 2018), 307-315.

17 Mediante Sentencia (Pleno) de 24 de mayo de 2018 (RTC 2018/54). 
requisito previo al procedimiento judicial. Así, la normativa europea en la materia ${ }^{18}$ establece la voluntariedad respecto de la eficacia de la resolución que se obtenga de ese procedimiento alternativo. Esto es, se otorga la posibilidad a las partes de que se atengan al resultado del procedimiento o bien no lo acaten y sometan el litigio a otro procedimiento, bien extrajudicial o judicial. No obstante, aquí también se le da a los Estados miembros cierto margen, puesto que se les permite que en sus legislaciones internas establezcan la obligatoriedad de someterse a la resolución que recaiga en el procedimiento alternativo, si bien esto sólo podrá ser obligatorio para los empresarios, nunca para el consumidor, con lo que dependerá de este, en cualquier caso, que la resolución tenga carácter vinculante o no.

En definitiva, el principio de voluntariedad rige, de acuerdo con la normativa vigente, en cualquier caso y para ambas partes respecto de la mediación y de cualquier otro procedimiento alternativo de resolución de conflictos en materia de consumo. Sin embargo, en aras de una mayor y mejor protección de los derechos de consumidores y usuarios, esa voluntariedad debería regir solamente para los consumidores, pero no para los comerciantes o empresas, que deberían venir obligados legalmente a someterse a ellos si ese es el deseo del consumidor, pues es la parte débil. Todo ello sin perjuicio, por supuesto, del derecho de ambas partes a acudir con posterioridad a la vía judicial, pues de lo contrario se estaría conculcando el derecho constitucional a la tutela judicial efectiva del artículo 24, pero sin olvidar que este no es el método más adecuado para satisfacer los intereses del consumidor.

Defensa y asesoramiento de las partes: Siguiendo con el orden del articulado de la Ley 7/2017, el artículo 10 regula los principios relativos a la defensa y asesoramiento de las partes en el marco de un procedimiento de resolución alternativa de litigios ${ }^{19}$. De acuerdo con este

18 Fundamentalmente la Directiva 2013/11 UE, y en concreto su artículo 9.2.a).

19 Esta postura viene avalada, además, por la jurisprudencia europea, ya que en este mismo sentido se pronuncia la Sentencia del Tribunal de Justicia de la Unión Europea de 14 de junio de 2017 (Sala 
artículo, las partes no podrán ser obligadas a acudir al procedimiento asistidas de abogado y procurador, de lo cual serán informados ambos litigantes por parte de la entidad de resolución alternativa de conflictos de que se trate en cada caso.

No obstante, esto no supone una prohibición, sino que cualquiera de las partes, ya sea el consumidor o ya sea el empresario, podrá actuar en el proceso con abogado y procurador, en cuyo caso tendrá que comunicarlo a la entidad en el plazo de los tres días siguientes a la presentación de la reclamación en el supuesto de que sea el consumidor quien haga uso de estas figuras o bien en ese mismo plazo de tres días desde la recepción de la reclamación en el caso del empresario.

Además, el segundo inciso del artículo reconoce a las partes el derecho de acceso a cualquiera de las fases del procedimiento, ya sea compareciendo por sí mismas o asistidas por un tercero, así como el derecho de solicitar asesoramiento independiente sobre el proceso cuando así lo estimen necesario.

La Sentencia del Tribunal de Justicia de la Unión Europea de 14 de junio de 2017 (Sala Primera): Si bien venimos centrándonos en el estudio de la normativa nacional en materia de resolución alternativa de litigios en los que intervienen consumidores, es necesario hacer un análisis de la jurisprudencia del Tribunal de Justicia de la Unión Europea en cuanto a la Directiva 2013/11. En concreto, nos centraremos en la Sentencia de 14 de junio de 2017 de la Sala Primera, puesto que este pronunciamiento se dirigía a analizar los principios de voluntariedad y de defensa y asesoramiento anteriormente explicados.

La mencionada sentencia se dicta en el marco de una cuestión prejudicial planteada por un tribunal italiano, en concreto, el Tribunale Ordinario di Verona, en relación con un procedimiento que enfrentaba al Banco Popolare Società Cooperativa contra los señores Livio Menini y

Primera), Asunto Livio Menini y María Antonia Rampanelli contra Banco Popolare Società Cooperativa (TJCE 2017\95). 
María Antonia Rampanelli. El asunto versaba sobre la reclamación que efectuaba el banco contra sus clientes por importe de 991.848'21 euros, cuantía que adeudaban en virtud de un contrato de apertura de crédito en cuenta corriente con garantía hipotecaria. Ante el requerimiento de pago del banco, los clientes presentaron oposición y solicitud de suspensión de las medidas de ejecución provisional que se les habían impuesto. La cuestión prejudicial que el Tribunal Ordinario de Verona remite al Tribunal de Justicia de la Unión Europea deriva precisamente de esa oposición al requerimiento de pago, puesto que entiende, que, en aplicación del Derecho italiano, esa oposición solo podría darse si se hubiera incoado con anterioridad un procedimiento de mediación.

Aun teniendo en cuenta que el fondo del asunto es importante para determinar ciertas cuestiones, como la condición de consumidores de las partes enfrentadas contra el banco, nos interesa más en este ámbito el contenido de la cuestión prejudicial planteada y, por supuesto, el de la sentencia que sobre ella se pronuncia.

Así, el Tribunal Ordinario de Verona plantea dos cuestiones prejudiciales. Una de ellas se desestima por entender el Tribunal de Justicia de la Unión Europea que sobre ello debe pronunciarse el órgano jurisdiccional nacional; sobre la segunda de las cuestiones, que es la que tiene importancia en nuestro estudio, se plantea un problema interpretativo de la Directiva 2013/11. Con ello, se cuestionan tres circunstancias que contempla el Derecho italiano. En primer lugar, si la Directiva 2013/11 se opone a que las legislaciones nacionales establezcan la obligatoriedad de someterse a un procedimiento de mediación hasta tal punto de constituirse como requisito de admisibilidad de la demanda judicial; en segundo lugar, si, además, se puede establecer, de acuerdo igualmente con la Directiva, la obligatoriedad para el consumidor de acudir a ese procedimiento de mediación bajo asistencia letrada; y, por último, si de nuevo la Directiva se opone a que el consumidor solo pueda decidir no someterse a la mediación en caso de que concurra alguna causa justificada. 
En cuanto a la primera cuestión, de si se puede predicar la obligatoriedad de la mediación como requisito previo a la vía judicial, el Tribunal italiano se pregunta si la posibilidad de que los Estados miembros así lo establezcan se refiere solo a aquellos conflictos que queden al margen de la aplicación de la Directiva, pues entiende que es esta la interpretación que puede efectuarse del tenor literal del artículo 1 de la Directiva 2013/1120. Ante este argumento, el Tribunal de Justicia de la Unión Europea responde que no solo hay que tener en cuenta la interpretación literal de los preceptos, sino que, tal y como acredita su propia y reiterada jurisprudencia, ha de tenerse en cuenta también el contexto y los objetivos que pretende alcanzar la normativa en cuestión. Así, teniendo en cuenta el tenor del precepto, pero también lo dispuesto en la Directiva 2008/52 del Parlamento Europeo y del Consejo, de 21 de mayo de 2008, sobre ciertos aspectos de la mediación en asuntos civiles y mercantiles ${ }^{21}$, el Tribunal de Justicia de la Unión Europea entiende que la voluntariedad en cuanto a la mediación no reside en el sometimiento del litigio a este sistema antes que al judicial, sino en que son las propias partes las que podrán estructurar, como deseen, el proceso, así como abandonarlo en cualquier momento, de tal modo que la cuestión importante en este ámbito es preservar el derecho de las partes a acceder al sistema judicial,

20 Artículo 1 de la Directiva 2013/11 del Parlamente Europeo y del Consejo, de 21 de mayo de 2013 relativa a la resolución alternativa de litigios en materia de consumo: "El objetivo de la presente Directiva es contribuir, a través de un alto nivel de protección del consumidor, al buen funcionamiento del mercado interior, garantizando que los consumidores puedan, si así lo desean, presentar reclamaciones contra los comerciantes ante entidades que ofrezcan procedimientos de resolución alternativa de litigios (en lo sucesivo, «procedimientos de resolución alternativa») que sean independientes, imparciales, transparentes, efectivos, rápidos y justos. La presente Directiva se entenderá sin perjuicio de la obligatoriedad de participar en este tipo de procedimientos prescrita en la legislación nacional, siempre que esta no impida a las partes ejercer su derecho de acceso al sistemajudicial".

21 En su artículo 5.2 establece que: "La presente Directiva no afectará a la legislación nacional que estipule la obligatoriedad de la mediación o que la someta a incentivos o sanciones, ya sea antes o después de la incoación del proceso judicial, siempre que tal legislación no impida a las partes el ejercicio de su derecho de acceso al sistema judicial”. Así como el considerando número 13 de la misma norma: "La mediación a que se refiere la presente Directiva debe ser un procedimiento voluntario, en el sentido de que las partes se responsabilizan de él y pueden organizarlo como lo deseen y darlo por terminado en cualquier momento. No obstante, el Derecho nacional debe dar a los órganos jurisdiccionales la posibilidad de establecer límites temporales al procedimiento de mediación; por otra parte, también deben poder señalar a las partes la posibilidad de la mediación, cuando resulte oportuno". 
que por otra parte se erige en derecho fundamental. Es por esto por lo que, si bien no se observa en modo alguno que esa obligatoriedad no compromete el cumplimiento de los objetivos de la Directiva 2013/11, sí que podría plantearse la conculcación del derecho a la tutela judicial efectiva, en tanto en cuanto es requisito previo para la admisión a trámite de una ulterior demanda. Sin embargo, a juicio del Tribunal de Justicia de la Unión Europea, esto no supone más que una limitación del derecho, pero en ningún caso la conculcación de este, con lo que, de acuerdo con su propia jurisprudencia, es perfectamente admisible, puesto que se considera una restricción proporcional al objetivo perseguido por ella. De hecho, no puede apreciarse de ningún modo una violación del derecho a la tutela judicial efectiva si se tiene en cuenta que las partes pueden retirarse en cualquier momento del procedimiento, que su resolución no es vinculante para las partes ${ }^{22}$, y que, además, los plazos de prescripción o caducidad de las acciones se suspenden en el transcurso del procedimiento de mediación, con el fin de no obstaculizar un posterior acceso a un procedimiento judicial.

En lo que respecta a la obligación impuesta por el Derecho italiano al consumidor de ser asistido por un abogado en los procedimientos de mediación, entiende el Tribunal de Justicia de la Unión Europea que, de conformidad con los artículos 8.b) y 9.1.b) de la Directiva, no es válida. Ello porque la norma comunitaria establece que los Estados deben velar por que el acceso a los procedimientos de resolución alternativa en materia de consumo sea sencillo, sin necesidad de asistencia letrada ni ningún otro tipo de asesoría jurídica, debiendo, de hecho, informarse a los consumidores de esta cuestión, no pudiendo ningún legislador nacional ir en contra de este principio.

22 No obstante, hay que tener en cuenta que el artículo 9.3 de la Directiva 2013/11 establece la posibilidad de que los Estados miembros, en sus legislaciones propias, dispongan que las resoluciones de los procedimientos de mediación tengan carácter vinculante para los comerciantes, si bien para ello el consumidor tendrá que estar de acuerdo con la resolución, puesto que para ellos en ningún caso podría ser vinculante. 
Por último, la tercera cuestión que planteaba el Tribunal Ordinario de Verona versaba sobre la posibilidad o no de los Estados miembros para obligar a los consumidores a someterse al procedimiento de mediación con carácter previo al acceso a la vía judicial y sin posibilidad de retirarse del mismo sin concurrencia de causa justificada para ello. Respecto a esta cuestión, el Tribunal de Justicia de la Unión Europea estipula que no cabe la posibilidad de contemplar esta obligatoriedad de mantenerse en el procedimiento de mediación a excepción de causa que justifique retirarse del mismo, puesto que, además, se contemplaban sanciones por ello en el procedimiento judicial que pudiera abrirse con posterioridad. Ello porque contraría el artículo 1 de la Directiva 2013/11, cuyo contenido ya se ha mencionado. Incluso en las legislaciones que obligan a los empresarios a someterse a estos procedimientos, no se puede contener este tipo de prescripciones, puesto que para el consumidor nunca podría ser obligatorio mantenerse en el procedimiento de mediación en ningún caso, puesto que de lo contrario sí se vería mermado el contenido del derecho a la tutela judicial efectiva.

En conclusión, y en lo que en nuestro estudio más nos interesa, queda claro en este pronunciamiento del Tribunal de Justicia de la Unión Europea que la obligatoriedad de sometimiento a procedimientos de resolución alternativa de litigios en materia de consumo es perfectamente válida. Es más, a nuestro juicio, no es solo válida, sino beneficiosa para el sistema y, sobre todo, para los consumidores.

Ahora bien, a modo de reflexión, entendemos que la obligatoriedad no debe predicarse de ningún modo en el caso de los consumidores, sino solo de los comerciantes o empresarios, pues son la parte dominante de las relaciones de las que surgen este tipo de litigios, con lo que no puede crearse la situación de que sigan siendo ellos quienes, en definitiva, tienen más opciones dentro del procedimiento, bien sea alternativo como la mediación o bien sea judicial. De esta forma se estaría desvirtuando un sistema que en principio se articula para otorgar una mayor protección al consumidor, ya que es quien la necesita, y no el empresario, que 
normalmente es quien impone su criterio y condiciones en todas las fases de la relación con el consumidor.

Coste y duración del procedimiento: Las cuestiones más relevantes en cuanto a los procedimientos de resolución alternativa de litigios en materia de consumo, desde el punto de vista del consumidor, son precisamente el coste y la duración de estos ${ }^{23}$. Y ello porque son estos aspectos los que disuaden, en su mayoría, a los consumidores de efectuar reclamaciones en vía judicial, ya que normalmente se trata de asuntos de escasa cuantía e importancia ${ }^{24}$. Es por esta razón por la que los artículos 11 y 20 de la Ley 7/2017 establecen que el proceso será gratuito en cualquier caso para el consumidor y que no excederá su resolución del plazo de noventa días naturales, respectivamente.

Profundizando en el aspecto del coste del procedimiento, la Directiva 2013/11, en su considerando 41 y en su artículo 8.c), propugna la gratuidad de los procedimientos de resolución alternativa de conflictos en materia de consumo, si bien abre la puerta a que se cobren costas. En todo caso, esas costas no deberán suponer impedimento alguno a la accesibilidad de los procedimientos, debiendo estos mantener su atractivo y seguir siendo asequibles, con lo que el coste no deberá exceder de una cuota mínima, simbólica. En este sentido, el proyecto de ley fijaba una cuantía máxima de treinta euros, que se reintegrarían al consumidor en caso de que su pretensión fuera totalmente satisfecha. Finalmente, esta previsión fue excluida y la vigente Ley 7/2017 establece la total gratuidad del procedimiento.

Como reflexión, el pago de una cuantía, aunque esta sea simbólica, en concepto de costas del procedimiento presenta tanto ventajas como

23 Esther Pillado González, "La mediación en materia de consumo", en Arbitraje y mediación en materia de consumo, dir. por Ester Pillado González (Madrid: Tecnos, 2012), 159 y 160.

24 Ello si se observa desde el punto de vista individualizado de cada consumidor, pues si ampliamos la perspectiva, pueden ser muchos los consumidores afectados por una práctica concreta de una o varias empresas que, finalmente, comporten que el asunto a tratar es de una magnitud mucho mayor. Sin embargo, lo que se trata, en definitiva, es de que los consumidores individualmente no se abstengan de reclamar por cuestiones como el coste o la duración del procedimiento, y es por estas razones por las que se articulan estos mecanismos. 
inconvenientes. Así, el abono de un precio, por bajo que fuera, impediría en cierto modo que se abusara del sistema. Además, señala la doctrina que su gratuidad podría comportar que las entidades de carácter privado que se plantearan solicitar su acreditación como entidades de resolución alternativa de litigios no lo hicieran por resultar el negocio poco o nada rentable, lo cual se evitaría con la imposición de una cantidad a las partes. Sin embargo, estas ventajas que supondría el cobro de una cuantía no compensan los inconvenientes que presenta, ya que ese gravamen comportaría un elemento disuasorio al consumidor a la hora de presentar una reclamación, puesto que, además, no se está teniendo en cuenta que la reclamación puede ser por una cuantía inferior a la que se pretende cobrar por el procedimiento. Además, en cuanto a las entidades, ese servicio puede ser ofrecido por entidades públicas, con lo que no se presentaría, a la postre, ningún problema al respecto.

Por último, en lo que respecta a la duración de los procedimientos, ese plazo de noventa días naturales que se ha referido anteriormente se contará desde la fecha de presentación de la reclamación, o bien desde la recepción de toda la documentación que se precise para la tramitación del procedimiento. Sin embargo, el propio artículo 20, en su segundo inciso, contempla la posibilidad de prórroga de ese plazo, sin que pueda ser superior al previsto para la resolución del litigio, cuando esté presente una especial complejidad.

Facilidad de acceso: La facilidad de acceso a los procedimientos de resolución alternativa de conflictos viene recogida, como principio, en el artículo 12 de la Ley 7/2017. A este respecto, se establece que el acceso a los procedimientos deberá ser sencillo, con independencia del lugar donde se encuentren las partes ${ }^{25}$ y también indistintamente del proceso de que se trate, contemplando incluso que pueda ser en línea. Además, el apartado segundo del artículo dispone que las oficinas y servicios de información y atención de las entidades de resolución alternativa,

25 Se refiere en concreto a los consumidores, pues serán quienes accedan al procedimiento, al menos con carácter general y mayoritario. 
deberán, en cualquier caso, diseñarse de tal modo que garanticen la accesibilidad universal a ellos, con la posibilidad de habilitar medios alternativos que aseguren el acceso a ellos por parte de personas con discapacidad o edad avanzada. Se entiende con esto que las entidades podrán habilitar medios electrónicos, pero que también tendrán que articular otros distintos para garantizar el acceso a los procedimientos de resolución alternativa a cualquier consumidor ${ }^{26}$.

Igualdad y contradicción: El artículo 19 de la Ley 7/2017 consagra los principios de igualdad y contradicción de las partes en los procesos de resolución alternativa de litigios en materia de consumo. En cuanto a la igualdad, se refiere el precepto a que se debe garantizar en el seno del procedimiento que se respeten las manifestaciones que las partes efectúen y que sus posiciones se mantengan equilibradas. Para hacer este principio efectivo, el artículo contempla la obligación de concederles a las partes un plazo suficiente para que formulen alegaciones, poniéndoselas en conocimiento a la otra parte mediante la documentación y demás pruebas, que podrán ser en formato electrónico, con que se hayan efectuado dichas alegaciones. Este intercambio de información entre las partes deberá garantizarse en todo momento, pudiendo hacerse por medios electrónicos o por cualquier otro método, y, además, deberá igualmente garantizarse el acceso al estado de la tramitación del procedimiento.

Eficacia de los acuerdos previos de sumisión a procedimientos de resolución alternativa de conflictos: Por último, respecto a los principios recogidos en la Ley 7/2017, es necesario analizar lo dispuesto en su artículo 15 referente a la validez y eficacia de los eventuales pactos a los que puedan llegar las partes con carácter previo al surgimiento del litigio relativos a la sumisión de estos a procedimientos de resolución alternativa

26 A este respecto, Iuliana Raluca Stroie, "Análisis de la Ley 7/2017, de 2 de noviembre, por la que se incorpora al ordenamiento jurídico español la Directiva 2013/11/UE, relativa a la resolución alternativa de litigios en materia de consumo", Revista CESCO de Derecho de Consumo 2 (2017): 7, DOI https://revista.uclm.es/index.php/cesco/index. 
de conflictos. Así, dicho artículo sostiene que, en cuanto al consumidor, este tipo de pactos no tendrá eficacia, no serán vinculantes para él, cuando el acuerdo declare su sumisión a un procedimiento con resultado vinculante. De ello podría desprenderse que, si ese pacto se refiere a la mediación de consumo, sí sería válido y eficaz, puesto que no se trata de un procedimiento con resultado. Sin embargo, el artículo 13 de la misma norma, se refiere precisamente a aquellos pactos de sumisión cuyo objeto sea un procedimiento de resolución alternativa con resultado no vinculante, estipulando lo mismo que el artículo 15, es decir, que estos no serán eficaces para el consumidor. Por otra parte, en lo que respecta al empresario, esos pactos previos de sumisión sí serán vinculantes, en tanto en cuanto cumplan con los requisitos que en cada caso se contemplen para cada acuerdo concreto, o, en su caso, cuando el empresario venga obligado legalmente a someterse al procedimiento o se haya adherido voluntariamente ${ }^{27}$, independientemente de que el pacto se refiera a un procedimiento con resultado vinculante o no.

Tanto el artículo 15 como el 13 de la Ley 7/2017 se basan en el artículo 10 de la Directiva 2013/11, que se refiere al principio de libertad. En virtud de este principio, el consumidor no podrá quedar en ningún caso vinculado por un pacto previo de sumisión a sistemas alternativos de resolución de conflictos cuando dicho pacto tenga como objetivo conculcar, de algún modo, el derecho que le ampara de acudir a la justicia ordinaria.

\subsubsection{Las entidades de resolución alternativa de litigios}

De acuerdo con lo dispuesto en la Directiva 2013/11, las entidades acreditadas van a ser las instituciones competentes para la resolución alternativa de litigios en materia de consumo. Es por ello por lo que todos los Estados miembros deberán garantizar la existencia de dichas entidades en un número suficiente como para hacer frente a todas las reclamaciones que puedan presentárseles, así como asegurar que cumplen con ciertos requisitos, que se establecen tanto en la normativa comunitaria

27 Como ocurre con la adhesión al sistema arbitral en materia de consumo. 
como en las diferentes legislaciones nacionales de cada Estado. Además de esos requisitos para las entidades, también se desarrollan una serie de exigencias que han de cumplir aquellas personas que vayan a ser las encargadas de la resolución de los procedimientos.

Requisitos exigibles para la acreditación de las entidades de resolución alternativa de litigios: Los requisitos relativos a la acreditación de las entidades de resolución alternativa de litigios se contienen en los artículos 5 a 7 de la Ley 7/2017 y el procedimiento a seguir por dichas entidades para lograr la acreditación se regula en los artículos 26 a 34 . Toda esta regulación se basa en lo expuesto por la Directiva 2013/11 de la Unión Europea, que exige unas obligaciones y estándares de calidad para que las entidades puedan adquirir la acreditación europea ${ }^{28}$.

Volviendo a la regulación española en la materia, se parte de la base de que podrán ser objeto de acreditación para llevar a cabo procedimientos de resolución alternativa de conflictos en materia de consumo entidades tanto públicas como privadas, de acuerdo con el artículo 3.1 de la Ley 7/2017, cuando estas entidades "propongan, impongan o faciliten una solución entre las partes en el ámbito de la resolución alternativa de litigios de consumo, nacionales o transfronterizos, relativos a obligaciones contractuales derivadas de contratos de compraventa o de prestación de servicios, y que voluntariamente soliciten su acreditación para ser incluidas en el listado nacional de entidades acreditadas que elabore la Agencia Española de Consumo, Seguridad Alimentaria y Nutrición”. Todas ellas deberán cumplir, en cualquier caso, con los requisitos exigidos. En primer lugar, deberán localizarse en el territorio español, entendiéndose por tal cuando la entidad en cuestión esté gestionada por una persona física o jurídica o por un ente público, debiendo tener todos ellos su centro de actividad o domicilio social en España. Igualmente, deberán

28 Dichas obligaciones, contenidas en los artículos 6 a 11 de la ya citada Directiva 2013/11, se refieren a: conocimientos especializados, independencia e imparcialidad de las personas físicas encargadas de la resolución alternativa de los litigios (artículo 6); transparencia de las entidades (artículo 7); eficacia y equidad de los procedimientos (artículos 8 y 9); libertad para someterse a ellos (artículo 10); y el cumplimiento del principio de legalidad (artículo 11). 
contar las entidades que quieran obtener acreditación con un estatuto o reglamento de funcionamiento, que además deberá contenerse en soporte duradero y estar accesible a los ciudadanos, con un contenido específico (información sobre su organización, financiación, tipo de litigios que resuelve, causas de inadmisión de reclamaciones y la relativa al procedimiento). Además, si la entidad en cuestión se va a encargar de procedimientos de resolución alternativa de litigios con resultado vinculante para el consumidor, su constitución deberá llevarse a cabo mediante ley o reglamento. Por último, las entidades deberán ofrecer procedimientos que tengan el fin de resolver litigios en materia de consumo, con carácter nacional o transfronterizo, ya sea en línea o no.

Requisitos exigibles a las personas encargadas de la resolución de los procedimientos gestionados por las entidades de resolución alternativa: Al igual que se le impone el cumplimiento de ciertos requisitos a la entidad para que pueda ser acreditada, también se le aplican una serie de exigencias que han de cumplir aquellas personas físicas que vayan a ser las encargadas de resolver los procedimientos gestionados por la entidad. Estas exigencias se regulan en los artículos 22 a 25 de la Ley 7/2017, y se refieren a su cualificación, imparcialidad y a los posibles conflictos de intereses que se puedan dar.

Así, en primer lugar, la persona encargada de resolver los procedimientos de resolución alternativa de litigios deberá estar en pleno ejercicio de sus derechos civiles, sin que pueda existir una sentencia que la inhabilite para el ejercicio de su profesión, ni incurrir en ningún tipo de incompatibilidad con respecto a su profesión habitual. Asimismo, deberán estas personas tener los conocimientos suficientes en la materia, esto es, en Derecho de Consumo y en concreto en la resolución alternativa o judicial de conflictos en los que intervengan consumidores, pero también deberán tener competencias suficientes en el Derecho en general. Por otra parte, deberán contar con un seguro que cubra la responsabilidad civil que pudiera surgir por su actuación en los procedimientos, 
pudiendo suscribirlo bien por sí mismas o bien, en su nombre, la entidad en la que actúen ${ }^{29}$.

Por otra parte, la ley trata de garantizar la imparcialidad de las personas encargadas de la resolución del conflicto en cualquier momento. Por ello, en el artículo 23 establece una serie de requisitos al respecto, como que no podrán ser nombradas por un período inferior a dos años y la imposibilidad de su remoción sin una causa plenamente justificada. Tampoco podrán, en ningún caso, recibir instrucciones de las partes, ni de sus representantes, con lo que se prevé también la prohibición de que la persona que vaya a intervenir en la resolución del conflicto haya mantenido una relación personal, profesional o comercial con ninguna de las partes en los tres años anteriores. Igualmente, para mantener esa imparcialidad se establece que las retribuciones por el ejercicio de sus funciones en el seno de la entidad de resolución alternativa de conflictos no podrán tener en cuenta el resultado de los procedimientos. No obstante, se prevé la posibilidad de que la resolución el litigio se le encargue a un órgano colegiado, en cuyo caso deberá constituirse mediante una representación paritaria de asociaciones de consumidores y usuarios y de asociaciones independientes, y también por una persona independiente, garantizándose de este modo la imparcialidad en estos supuestos.

Seguidamente, en el artículo 24, se regulan las circunstancias relativas a los casos en que surja un conflicto de intereses en la persona encargada de la resolución con respecto a las partes en conflicto. En primer lugar, la persona interviniente en el litigio deberá comunicar inmediatamente y en cualquier momento a lo largo de todo el procedimiento toda aquella circunstancia que pudiera provocar un conflicto de intereses o que pudiera cuestionar de algún modo su independencia o imparcialidad. Si se comprobara que realmente la circunstancia comunicada da lugar a un conflicto de intereses o pone en peligro la imparcialidad de la persona

29 No obstante, no se les aplicará esta última obligación a aquellas entidades de resolución alternativa de litigios que tengan carácter público, ni tampoco a las personas que resuelvan los procedimientos que ellas gestionen. 
que va a resolver el procedimiento, esta deberá abstenerse de proseguir con la tramitación de este y se nombrará a un sustituto. Si esa sustitución resultara imposible, la entidad pondrá en conocimiento de las partes estas circunstancias, pudiendo continuar con el procedimiento dirigido por la persona que presenta el conflicto de intereses siempre que ninguna de ellas se oponga. En caso contrario, es decir, si alguna de las partes se opone, deberán ser informadas ambas de que pueden iniciar otro procedimiento de resolución alternativa ante otra entidad acreditada competente para el conocimiento del supuesto ${ }^{30}$.

Finalmente, se prevén, tal y como expone la rúbrica del artículo 25, garantías adicionales referentes a la imparcialidad cuando las personas encargadas de la resolución del litigio sean empleadas por asociaciones empresariales u organizaciones profesionales de las cuales sea miembro el empresario reclamado. En este supuesto, se deberá probar que hay “un presupuesto independiente, específico y suficiente para el cumplimiento de sus funciones". No obstante, esta garantía adicional no se exigirá cuando de la resolución del conflicto se encargue un órgano colegiado cuyos miembros sean representantes de esa organización o asociación empresarial que los haya empleado y los retribuya y de la organización de consumidores elegida por la entidad, pues se entiende que en este caso se garantiza la imparcialidad del órgano de manera suficiente.

30 A pesar de esta posibilidad de plantear el conflicto ante otra entidad competente, se contempla también que la falta de imparcialidad o independencia de la persona encargada de resolver el litigio pueda derivar o ser consecuencia de una mala práctica por parte de la entidad. Si alguna de las partes entendiera que es este el caso, podrá presentar ante la propia entidad una reclamación al respecto, y esta deberá trasladarla a la autoridad competente. Además, todo ello es independiente del hecho de que las partes podrán retirarse del procedimiento si no están conformes respecto a su funcionamiento o tramitación, de acuerdo con lo expuesto en el artículo 14.1.a) de la Ley 7/2017. 
4. LA RESOLUCIÓN DE CONFLICTOS ONLINE EN MATERIA DE CONSUMO. LA PLATAFORMA EUROPEA DE RESOLUCIÓN DE LITIGIOS EN LÍNEA

La resolución de litigios online se ha venido desarrollando en los últimos tiempos y cuenta con una legislación propia en la materia, lo cual ha venido obviamente motivado por los numerosos avances tecnológicos que se han dado desde finales del siglo XX, los cuales han comportado numerosos problemas para los cuales se han tenido que articular nuevos sistemas de resolución. Sin embargo, a la mediación en concreto no se le han aplicado esos avances en la técnica. El porqué de esta cuestión se encuentra, de acuerdo con la doctrina más autorizada ${ }^{31}$, en la reticencia a dejar de un lado la base de las humanidades y las ciencias sociales para dejarle paso a la tecnología y, además, el miedo a que la aplicación de esa tecnología pueda resultar heterodoxa y perjudique a lo ya logrado en el campo de la resolución alternativa de litigios. Sin embargo, no se puede olvidar que, pese a estos eventuales inconvenientes, son numerosas las ventajas que presentaría una adecuación de la tecnología a los medios de resolución de litigios y, en concreto, a la mediación, por ser este el método que mejores resultados presenta en la práctica.

Teniendo en cuenta todo ello, también es cierto que la mediación electrónica obtuvo un reconocimiento legal ya con la Ley 5/2012, de 6 de julio, de mediación en asuntos civiles y mercantiles ${ }^{32}$, si bien, como ya se ha explicado, no resultaba aplicable a los conflictos con consumidores. Esta norma permitía que las partes, voluntariamente, acordasen que todas o algunas de las actuaciones del procedimiento de mediación se desarrollaran por medios electrónicos, estableciendo la preferencia de que se realizara así cuando las reclamaciones fueran sobre una cantidad inferior

31 Carlos Vázquez De Castro, "La mediación electrónica y los medios disponibles aún a explorar: estado de la cuestión" en La resolución de conflictos con consumidores: de la mediación a las ODR, dir. por Inmaculada Barrals Viñals (Madrid: Reus, 2018), 133.

32 De hecho, en el proyecto de Ley de mediación en asuntos civiles y mercantiles, de 8 de abril de 2011, en su artículo 25.2, se establecía la mediación electrónica como obligatoria. Sin embargo, nunca llegó a promulgarse efectivamente la ley. 
a 600 euros. Sin embargo, las estadísticas muestran que estas previsiones legales no han sido aplicadas efectivamente en la práctica.

Por otra parte, igualmente la Ley 5/2012 mencionaba el concepto de mediación simplificada, quedando definida en su Disposición Final Séptima. Así, se entiende por mediación simplificada aquella que, siendo promovida por el Gobierno a iniciativa del Ministerio de Justicia, se desarrolla íntegramente por procedimientos electrónicos, debiendo consistir, necesariamente, en una reclamación de una cantidad. A pesar de ese mandato a los poderes públicos que hace la ley, en la práctica se dejó la promoción de este método a la iniciativa privada, con lo que su implantación no ha sido eficaz, ya que, sin la iniciativa y apoyo públicos, el ciudadano no confía en el sistema33.

En lo que respecta a la materia de resolución de litigios por estos medios en materia de consumo, no hay una regulación sustantiva de la mediación electrónica, y encontramos la problemática de no poder aplicar lo dispuesto en la Ley 5/2012 en este ámbito. Sin embargo, no se presentaría en la práctica ningún problema a la hora de aplicar la tecnología prevista en dicha ley a los litigios con consumidores, más allá de la necesaria protección a sus derechos. La cuestión es que, doctrinal y legalmente, se separan la resolución de conflictos online y la resolución alternativa de los mismos. Si bien conceptualmente es necesario diferenciarlos porque presentan características propias, no trasciende a la práctica esa diferencia, puesto que son sustantivamente lo mismo ${ }^{34}$. Teniendo esto presente, cabe preguntarse por qué no se aplican los conceptos de mediación electrónica y mediación simplificada de la Ley 5/2012 a la materia de consumo, puesto que ambas instituciones se aplican a reclamaciones de cantidad que, usualmente, son de escasa cuantía, lo cual encaja

33 Al respecto, Vázquez De Castro, "La mediación electrónica...", 139.

34 En este sentido, Vázquez de Castro, "La mediación electrónica...", 143. El autor señala que "mantener esto -que los sistemas electrónicos de resolución de conflictos son una nueva categoría sui generis- es tanto como afirmar que la naturaleza de los contratos muta por el hecho de utilizar la tecnología para su perfección o para su consumación. La compraventa o el arrendamiento son contratos que no quedan desnaturalizados con independencia de que se realicen presencialmente o por comunicaciones electrónicas". 
perfectamente en las reclamaciones que los consumidores habitúan a interponer, con lo que el empleo de estos métodos es idóneo.

De hecho, el uso de la mediación electrónica o la mediación simplificada presentaría ventajas en el campo del Derecho de Consumo. En primer lugar, se puede dar una valoración positiva al hecho de la interacción asíncrona, esto es, las partes no interactúan simultáneamente como ocurre en la mediación presencial, y, además, lo hacen por escrito. Ambas cuestiones, la asincronía y la forma escrita, sumadas a la intervención del mediador, comportan que el conflicto pueda resolverse de una manera mucho más calmada, con menos posibilidades de que se generen reacciones excesivas de alguna de las partes y se agrave aún más la situación. Por otra parte, el hecho de llevar a cabo el procedimiento por medios electrónicos posibilita tener todas las comunicaciones que se efectúan registradas y delimitadas, puesto que se realiza mediante formularios online, con lo que no caben reformulaciones de las partes que aumenten la complejidad del litigio en cuanto a su resolución. Esto facilita enormemente la labor del mediador, que, por estos métodos, además, le resulta más sencillo saber en qué punto está cada una de las partes y si realmente puede lograrse un acuerdo, puesto que las comunicaciones privadas siempre van a ser más sinceras que si se efectúan en público con la contraparte presente. Por último, se observaría una disminución en los costes, ya de por sí bajos, del procedimiento de mediación, pues no serían necesarios gastos en tramitación y convocatoria a las partes, ya que todo ello se llevaría a cabo por medios electrónicos.

Prueba de que la mediación electrónica funciona la encontramos en Estados Unidos, donde, a pesar de tener una legislación bastante pobre en cuanto a la protección de consumidores se refiere si la comparamos con la de la Unión Europea, el empleo de estos métodos es muy común. Las empresas los usan, a nivel interno, tanto en sus disputas de carácter mercantil con otras empresas, como con los conflictos que puedan surgir con los consumidores. De hecho, se emplea incluso como ventaja competitiva frente a aquellas empresas que no hacen uso de la mediación 
electrónica, pues los consumidores suelen quedar satisfechos y no vetan a la empresa con la que han tenido el conflicto por haberlo resuelto de una manera sencilla, rápida y sin coste para ellos.

Puede concluirse, por tanto, que la adopción de sistemas de mediación electrónica en los litigios con consumidores es verdaderamente útil y debería desarrollarse, ya que se trata normalmente de reclamaciones de cuantías muy pequeñas y el asunto suele estar muy bien delimitado. No obstante, ello no supone que no debieran ejercerse controles, sino que los consumidores deberían estar en todo momento informados sobre el procedimiento, al igual que sucede en la mediación tradicional, y, además, no podrá dejarse todo el proceso al libre arbitrio de las empresas, puesto que esto pondría en peligro la protección de los derechos del consumidor. Igualmente, en este ámbito se plantean las mismas cuestiones de las que ya se ha hablado con anterioridad, como el problema de la voluntariedad frente a la obligatoriedad o la necesidad de que el mediador sea imparcial.

Por último, es destacable que, a pesar de la inacción por parte de los poderes públicos en la materia, es cierto que las entidades privadas sí han ido desarrollando sistemas que se pueden definir como de mediación electrónica. En España encontramos algunos ejemplos, como Ejustic, Solvo o Youstice35; y también en el ámbito de empresas privadas que articulan sistemas internos de mediación, como el que tiene $e B a y$.

La Plataforma Europea de resolución de litigios en línea: Dado que los principales motivos por los que se articulan los sistemas de resolución alternativa de litigios en materia de consumo son la rapidez del procedimiento y su bajo coste frente a la vía judicial, es lógico que hayan surgido y estén desarrollándose estos medios de resolución de conflictos en el ámbito electrónico con el fin de llevarlos a cabo online. La Directiva 2013/11, así como la norma española que la traspone, la Ley 7/2017,

35 Disponibles en internet; respectivamente: http://www.ejustic.com/ [acceso el 2 de abril de 2020]: http://www.odrsolvo.com/ [acceso el 2 de abril de 2020]; y https://www.youstice.com/es/ [acceso el 2 de abril de 2020]. 
contemplan, a lo largo de todo su articulado, la posibilidad de que las entidades acreditadas presten sus servicios de manera electrónica, de tal modo que los plazos de resolución se agilizan y disminuyen de manera notable los costes que se derivan del procedimiento, pues las partes no necesitan estar físicamente presentes y, además, se transmite toda la información por medios electrónicos.

Como ejemplo de esta tendencia a la digitalización del procedimiento por las facilidades y ventajas que presenta, encontramos la Plataforma Europea de resolución en línea de litigios, que se refiere a aquellos conflictos con carácter transfronterizo que se hayan producido en el marco del comercio electrónico. Esta plataforma se arbitra con el fin de poner a disposición de los consumidores un medio de resolución alternativa de los conflictos que puedan tener con empresarios, ya sea para tramitar procedimientos con resultados vinculantes, como es el arbitraje, o procedimientos con resultado no vinculante, como la mediación, pero en ningún caso podrá emplearse la Plataforma Europea de resolución en línea de litigios para tramitar procedimientos jurisdiccionales ${ }^{36}$.

El sistema de la Plataforma Europea se adopta a raíz de la promulgación del Reglamento 524/2013, del Parlamento Europeo y del Consejo, de 21 de mayo de 2013, sobre resolución de litigios en línea en materia de consumo, por lo que para delimitar el ámbito de actuación de la Plataforma se deberá tener en cuenta el ámbito de aplicación de esta norma, que es más restrictivo que el de la Directiva 2013/11. Así, el Reglamento $524 / 2013$ se limita a las reclamaciones que deriven de relaciones de comercio electrónico o e-commerce, de lo cual se deduce que solo podrá emplearse la Plataforma para aquellos litigios surgidos por contratos celebrados en línea. Además, en el caso de España, el ámbito de actuación de la plataforma se condiciona por lo dispuesto en la Ley 7/2017. En este sentido, no se admite en nuestro ordenamiento la posibilidad de que el

36 En este sentido se pronuncia Félix Valbuena González, "La plataforma europea de resolución de litigios en línea (ODR) en materia de consumo", Revista de Derecho Comunitario Europeo 52 (2015): 1003 . 
empresario pueda ser quien presente la reclamación 37, y, además, el litigio deberá ser transfronterizo ${ }^{38,39}$.

La Plataforma Europea de resolución de litigios en línea en materia de consumo tiene una función canalizadora de las reclamaciones efectuadas por consumidores con domicilio en la Unión Europea con respecto a comerciantes igualmente domiciliados en la Unión Europea. Así, el consumidor podrá presentar su reclamación en la web de la Plataforma, que es gestionada por la Comisión Europea, y esta la remitirá tanto al empresario ${ }^{40}$ a quien se dirige la reclamación como a la entidad de resolución alternativa de litigios que resulte competente en el caso concreto. Esto significa, esencialmente, que la Plataforma no gestiona ni resuelve los procedimientos derivados de las reclamaciones que se le presentan, sino que solo se encarga de transmitir esas reclamaciones a las entidades competentes para su resolución ${ }^{41}$. Por ello, sus funciones son las de facilitar formularios de reclamación online en todas las lenguas oficiales de la Unión Europea y el traslado de las reclamaciones a la parte reclamada y a la entidad que determine competente. Sin embargo, también se le atribuyen ${ }^{42}$ a la Plataforma otras funciones, cuales son las de ofrecer a las entidades, de manera gratuita, un sistema electrónico para la

37 Esta bidireccionalidad del conflicto sí se permite en el Reglamento 524/2013 del Parlamento Europeo y del Consejo, de 21 de mayo de 2013, sobre resolución de litigios en línea en materia de consumo, concretamente en su artículo 2.2, pero lo condiciona a lo que disponga al respecto la legislación de cada Estado miembro. Además, sólo se permite esa bidireccionalidad en los casos de Alemania, Bélgica, Luxemburgo y Polonia.

38 A nuestro juicio, esta previsión no es coherente con el espíritu de la ley y de la normativa en materia de protección al consumidor en general, en tanto en cuanto el objetivo es, en esencia, facilitar medios rápidos, efectivos y que presenten un menor coste para el consumidor, dado que de lo contrario se observa una reticencia a reclamar. El hecho de que no se permita el acceso a la Plataforma Europea a litigios de carácter nacional es un obstáculo para los consumidores, que tienen que buscar otros medios para efectuar sus reclamaciones. Este es el caso español y el de la mayoría de Estados miembros, pues solo se permite el acceso de reclamaciones por litigios nacionales a la Plataforma en Alemania y Bélgica. 39 En relación con esta cuestión, Lorenzo Bujosa Vadell y Diego Palomo Vélez, "Mediación electrónica: perspectiva europea", Revista Ius et Praxis 2 (2017): 62.

40 Los comerciantes europeos que estén adheridos a una entidad de resolución alternativa de litigios tienen la obligación de incluir en sus sitios web un enlace a la Plataforma Europea de resolución de litigios en línea. En el ordenamiento jurídico español, esta obligación se contiene en el artículo 40 de la Ley $7 / 2017$.

41 En este sentido, Jesús Conde Fuentes, "La plataforma europea de resolución de litigios en línea ¿alternativa efectiva para los consumidores?", Revista General de Derecho Procesal 50 (2020): 7. 42 Mediante el artículo 6 del Reglamento 524/2013, del Parlamento Europeo y del Consejo, de 21 de mayo de 2013, sobre resolución de litigios en línea en materia de consumo. 
tramitación online del procedimiento, si bien dichas entidades no están obligadas a emplearlo; facilitar a las partes en conflicto la traducción de la información que ambas faciliten a lo largo del procedimiento cuando esta sea necesaria para su resolución; articular mecanismos que permitan a las partes y a las entidades valorar el funcionamiento de la Plataforma; y proporcionar datos estadísticos de los resultados de los litigios sometidos a la Plataforma, así como información de los procedimientos de resolución alternativa, de las entidades y del modo de presentación de las reclamaciones.

En definitiva, la Plataforma Europea simplemente gestiona la transmisión de la reclamación al empresario y a la entidad que designe ella misma competente, pero no el procedimiento en sí. De ello se encargará la entidad de resolución alternativa de litigios acreditada, rigiéndose por tanto el procedimiento de acuerdo con las normas en la materia del Estado miembro en que radique dicha entidad43. Por ello, la mayoría de reclamaciones que se presentan por vía de la Plataforma Europea en las que la entidad competente se encuentra en España, se solventan mediante el arbitraje de consumo, dado que el uso de la mediación en la materia no está aún asentado. Sin embargo, la doctrina 44 apunta a que, si bien es evidente la utilidad que presenta la posibilidad de tramitar las reclamaciones de consumidores por vía electrónica, especialmente en los supuestos de conflictos transfronterizos, la Plataforma no aplica todos los avances técnicos de los que se dispone actualmente, con lo que el sistema pierde en calidad y eficacia por no desarrollarse con el correcto nivel técnico.

43 Conde Fuentes, "La plataforma europea de resolución de litigios..., 8.

44 A este respecto, Inmaculada Barrals Viñals, "La plataforma de resolución de litigios en línea de la UE y las entidades de resolución/mediación acreditadas: ¿mucho ruido y pocas nueces?”, en $L a$ resolución de conflictos con consumidores: de la mediación a las ODR. Dirigido por Inmaculada Barrals Viñals (Madrid: Reus, 2018), 97-130. 


\section{CONCLUSIONES}

Primera. La mediación es un medio de resolución de litigios en el que dos o más partes tratan de alcanzar por sí mismas un acuerdo con la intervención de un mediador, sometiéndose al procedimiento de manera voluntaria. Si bien el concepto es discutible, es el que empleamos en nuestro estudio por ser el concepto que ofrece la ley de mediación.

Segunda. La mediación se diferencia claramente de otros medios de resolución de litigios, ya sean heterocompositivos (jurisdicción o arbitraje) o autocompositivos. La diferencia de la mediación con respecto a los primeros radica en la eficacia de la decisión, pues el resultado de la mediación no es vinculante, mientras que en los sistemas heterocompositivos sí lo es. En cuanto a los medios autocompositivos, encontramos la conciliación, cuya diferencia con la mediación es que en este caso se produce en el marco de un procedimiento judicial, para evitarlo o para finalizarlo; y la negociación, que se diferencia porque en esta última no interviene un tercero como sí lo hace en la mediación.

Tercera. La Ley 5/2012 regula todo lo relativo a la mediación en asuntos civiles y mercantiles (principios rectores, sujetos intervinientes, la figura del mediador, el procedimiento, etcétera). Sin embargo, en un primer momento, esta norma excluía de manera expresa la mediación de consumo de su ámbito de aplicación. En otras palabras, se prohibía mediante esta ley la mediación en aquellos litigios en los que intervinieran consumidores.

Cuarta. Teniendo en cuenta esa prohibición, la evolución legislativa en la materia nos lleva a hablar de la Directiva 2013/11/UE del Parlamento Europeo y del Consejo, de 21 de mayo de 2013, relativa a la resolución alternativa de litigios en materia de consumo, pero más concretamente de la norma que la traspone a nuestro ordenamiento, cual es la Ley 7/2017, de 2 de noviembre, relativa a la resolución alternativa de litigios en materia de consumo. Ambas normas contemplan la posibilidad 
de seguir un procedimiento de mediación cuando se trate de litigios en materia de consumo.

Quinta. En cualquier caso, la mediación de consumo, así como cualquier otro medio de resolución alternativa de litigios en la materia, deberá llevarse a cabo sujetándose a una serie de principios que se contienen a partir del artículo 8 de la Ley 7/2017. Estos principios, que se recogen en la norma como requisitos del procedimiento, son relativos a: la voluntariedad, la defensa y asesoramiento de las partes, el coste y la duración del procedimiento, la facilidad de acceso, la igualdad y la contradicción de las partes y la ineficacia para el consumidor de los acuerdos previos de sumisión a procedimientos de resolución alternativa de conflictos.

Si bien todos esos principios, sumados a los generales de independencia, imparcialidad, transparencia, eficacia y equidad, son absolutamente indispensables en cualquier procedimiento de mediación de consumo, es de especial trascendencia el referente a la voluntariedad.

Sexta. En España se optó por mantener un sistema de absoluta voluntariedad en cuanto al sometimiento al proceso de mediación, a pesar de que la Directiva 2013/11 daba la opción de que los Estados miembros pudieran establecer la obligatoriedad para las empresas (nunca para los consumidores). Ello supone una disminución en la protección al consumidor, pues, en definitiva, se está dejando en manos de la empresa, que es la parte preponderante de la relación, la decisión de someterse a un procedimiento alternativo para la resolución del litigio (que es más beneficioso para el consumidor) o bien seguir los trámites de un procedimiento jurisdiccional.

Séptima. Creemos firmemente que imponer al empresario la obligación de someterse al procedimiento de mediación antes de poder acudir a la vía judicial es sumamente favorable a la protección del consumidor, pues de hecho así lo prueban los datos estadísticos de los países que sí lo han establecido. La solución en el ordenamiento jurídico español podría 
venir dada por las competencias que en la materia han adquirido las Comunidades Autónomas.

De este modo, apostamos por la aprobación de leyes autonómicas que establezcan la obligatoriedad para el empresario de someter el litigio a un procedimiento de mediación, o, al menos, la obligación de asistencia a una sesión informativa previa, siempre que el consumidor así lo desee. Ejemplo de esta cuestión lo encontramos en el Código de Consumo de Cataluña, que aprobó una reforma que incluía la obligatoriedad de sometimiento a la mediación como requisito de procedibilidad para el empresario en los casos de reclamaciones por créditos hipotecarios.

Octava. La Ley 7/2017 prevé que la gestión de los procedimientos de resolución alternativa de conflictos en materia de consumo se lleve a cabo a través de las entidades de resolución alternativa de litigios que se acrediten conforme a los requisitos que la propia ley establece. A este respecto, podrán acreditarse como entidades de resolución alternativa de litigios en materia de consumo entidades públicas o privadas, que estén localizadas en España y que cuenten con un estatuto o reglamento de funcionamiento. La competencia para la acreditación corresponde a la Agencia Española de Consumo, Seguridad Alimentaria y Nutrición.

Novena. Al igual que los requisitos que se les exigen a las entidades para poder ser acreditadas, también se contemplan una serie de requisitos para las personas que vayan a encargarse de la resolución de los litigios que gestionen esas entidades. Igualmente, se recogen en la Ley 7/2017, y se refieren a su cualificación profesional, su imparcialidad y a las actuaciones que deberán llevar a cabo en caso de que se plantee un conflicto de intereses en el transcurso de un procedimiento.

Décima. A pesar de que la resolución alternativa de conflictos a través de medios electrónicos es una realidad desde hace tiempo, no se le han aplicado los avances tecnológicos pertinentes a la mediación. La mediación electrónica se contempla en la Ley 5/2012 respecto a asuntos 
civiles y mercantiles, pero no se desarrolla este aspecto en la Ley 7/2017, con lo que no existe como tal una mediación electrónica de consumo.

La práctica en países como Estados Unidos demuestra que el empleo de estas técnicas de resolución de conflictos resulta muy beneficiosa y útil en cuanto a protección de los consumidores, con lo que tanto el ordenamiento jurídico europeo como, por consecuencia, el español, deberían comenzar a introducir los medios necesarios para institucionalizar la mediación electrónica en materia de consumo, puesto que en el ámbito privado sí se ha desarrollado.

Undécima. Como primeros atisbos de un desarrollo real de un sistema de mediación electrónica institucionalizado, encontramos la Plataforma Europea de resolución de litigios en línea, que funciona como transmisora de las reclamaciones que se le presenten. Así, cuando un consumidor efectúa una reclamación a través de la Plataforma, esta se la comunica al empresario a quien se reclama y también a la entidad de resolución alternativa de litigios que resulte competente en cada caso.

En el caso de España, para poder presentar una reclamación por esta Plataforma, deberá tratarse de un conflicto transfronterizo, lo cual supone una merma en la protección del consumidor.

\section{REFERENCIAS BIBLIOGRÁFICAS}

Agüero Ortiz, Alicia. “La transposición de la Directiva 2013/11/UE al ordenamiento jurídico español a través de la Ley 7/2017 de 2 noviembre”. En La resolución de conflictos con consumidores: de la mediación a las $O D R$, dirigido por Inmaculada Barrals Viñals, 41-74. Madrid: Reus, 2018.

Barrals Viñals, Inmaculada. "La plataforma de resolución de litigios en línea de la UE y las entidades de resolución/mediación acreditadas: ¿mucho ruido y pocas nueces?”. En La resolución de conflictos con 
consumidores: de la mediación a las $O D R$, dirigido por Inmaculada Barrals Viñals, 97-130. Madrid: Reus, 2018.

Bujosa Vadell, Lorenzo y Diego Palomo Vélez, "Mediación electrónica: perspectiva europea”, Revista Ius et Praxis 2 (2017): 51-78.

Carretero Morales, Emiliano. La mediación civil y mercantil en el sistema de justicia. Madrid: Dykinson, 2016.

Conde Fuentes, Jesús. "El procedimiento extrajudicial para la restitución de las cantidades pagadas en aplicación de las cláusulas suelo", $R e$ vista de Derecho Civil 4 (2017): 219-233.

Conde Fuentes, Jesús. "La adaptación del derecho español al marco europeo de resolución alternativa de litigios en materia de consumo", en Adaptación del Derecho procesal español a la normativa europea y a su interpretación por los tribunales, dirigido por Fernando Jiménez Conde, 307-315. Valencia: Tirant lo Blanch, 2018.

Conde Fuentes, Jesús. "La plataforma europea de resolución de litigios en línea calternativa efectiva para los consumidores?”. Revista General de Derecho Procesal 50 (2020): 1-21.

Díez-Picazo Giménez, Ignacio. "El arbitraje y la mediación”. En Curso de Derecho Procesal Civil II. Parte Especial, dirigido por Andrés de la Oliva Santos y Jaime Vegas Torres, 585-612. Madrid: Editorial Universitaria Ramón Areces, 2014.

Esteban De La Rosa, Fernando. "La vertebración del régimen español de la mediación de consumo en el marco del Derecho europeo", Revista de los Estudios de Derecho y Ciencia Política 25 (2017): 1-28.

Pillado González, Esther. "La mediación en materia de consumo". En Arbitraje y mediación en materia de consumo, dirigido por Ester Pillado González. Madrid: Tecnos, 2012.

Raluca Stroie, Iuliana. “Análisis de la Ley 7/2017, de 2 de noviembre, por la que se incorpora al ordenamiento jurídico español la Directiva 
2013/11/UE, relativa a la resolución alternativa de litigios en materia de consumo". Revista CESCO de Derecho de Consumo 2 (2017): 127 ,

Soleto Muñoz, Helena. "La mediación conectada con los tribunales". En Mediación y resolución de conflictos. Técnicas y ámbitos, coordinado por Emiliano Carretero Morales y Cristina Ruíz López, 493-510. Madrid: Tecnos, 2017.

Valbuena González, Félix. "La plataforma europea de resolución de litigios en línea (ODR) en materia de consumo”. Revista de Derecho Comunitario Europeo 52 (2015): 987-1016.

Vázquez De Castro, Carlos. "La mediación electrónica y los medios disponibles aún a explorar: estado de la cuestión” en La resolución de conflictos con consumidores: de la mediación a las $O D R$, dirigido por Inmaculada Barrals Viñals, 131-158. Madrid: Reus, 2018.

Elvira Marugán Escobedo elvira.marugan@gmail.com https://orcid.org/oooo-0003-3905-093X 
